\section{AS PRÁTICAS RESTAURATIVAS E SUAS POSSIBILIDADES NA ESCOLA: PRIMEIRASAPROXIMAÇÕES}

\author{
Restorative Practices and School: First Aproaching \\ La Justicia Restaurativa y sus Posibilidades en la Escuela: \\ Primeras Aproximaciones
}

\author{
Les Pratiques de Justice Réparatrice et ses Possibilités à \\ L'école: Premières Approches
}

\begin{abstract}
Resumo
A violência na escola tem merecido uma série de pesquisas com o propósito de compreender suas origens, sua dinâmica e pensar formas de atuação possíveis que venham a fazer da escola um lugar contra a barbárie e não produtor da barbárie, como nos ensina Theodor W. Adorno. Tendo tomado contato com certas modalidades de intervenção, interessamo-nos por investigar as Práticas Restaurativas que vêm sendo pensadas e aplicadas em diversas partes do mundo. Apresentaremos então um breve histórico dessas práticas, seu surgimento, suas modalidades existentes, sua expansão para alguns países, retomando alguns de seus pressupostos conceituais e técnicos utilizados no manejo de situações de conflito. Também apresentaremos o momento em que a discussão a respeito da Justiça Restaurativa chega ao Brasil e as primeiras experiências em território nacional. Nosso interesse primordial é relatar algumas experiências de mediação de conflitos escolares e comunitários, pensando o que trazem essas experiências de contribuição para a reflexão a respeito da violência como barbárie. O antídoto para a barbárie está na aposta feita de que é pelo esclarecimento, pela formação intelectual, racional, pela palavra em oposição à força física,que é possível preservar a finalidade humana em todas as suas ações. A partir disso, analisamos as práticas restaurativas não deixando de enxergar seu alcance e seus limites.
\end{abstract}

Palavras-chave: violência; escola; justiça restaurativa; teoria crítica; mediação de conflito.

\begin{abstract}
School violence has been studied to understanding its source, its dynamic and changings possibilities for many researches. In other way, Restourative practices have been used on schools to prevent many violences aspects. So, in this article, it has intended to present the history, conceptions, and technics on restourative practices, used to deal with a lot of differents situations, specially, in Brasil, and their possibilities as an alternative way to deal with violence on school in that country. In this way, there is as a brief history of these practices around the world, so the manner it has been introduced in which country. One of the most important Restourative practices conceptions is the belief that the dialogue can replace the violence. Thus, it has been studied how some restourative practices can be a pacific way to deal with school and social conflicts in order to fight against the barbarism, as in Theodor W. Adorno works. In such way, it has been analyzed the restorative practices to considering their limits and ranges.
\end{abstract}

Keywords: violence; school; restorative justice; critical theory; conflict mediation.

\section{Resumen}

La violencia en la escuela ha merecido una serie de estudios con el propósito de comprender sus orígenes, su dinámica y pensar formas de actuación posibles. La Justicia Restaurativa viene destacándose en todo el mundo, como una forma de intervenir en las situaciones de violencia escolar. El interés primordial de este artículo fue pensar cómo las prácticas y

Artigo Original

. .
}


los principios teóricos de la Justicia Restaurativa pueden ser utilizados en el enfrentamiento de los conflictos escolares. Para eso, se presentará una breve historia de las prácticas restaurativas, especialmente de la Justicia Restaurativa del Brasil, retomando algunos de sus presupuestos conceptuales y técnicos, utilizados en el manejo de situaciones de conflicto. El interés principal es informar algunas experiencias de mediación para la escuela y los conflictos comunitarios, teniendo en cuenta lo que aportan estas experiencias para contribuir a la reflexión sobre la violencia y la barbarie. El antídoto a la barbarie es la apuesta que es la aclaración, el intelectual, la formación racional, la palabra en lugar de la fuerza fisica, es posible preservar propósito humano en todas sus dimensiones. De esto, se analizan las prácticas restaurativas no ven salir de su alcance y límites.

Palabras clave: violencia; escuela; justicia restaurativa; teoría crítica; mediación de conflitos.

\section{Résumé}

La violence dans les écoles a reçu beaucoup de recherche afin de comprendre ses origines, sa dynamique et ses façons de penser des actions possibles qui feront de l'école un lieu contre la barbarie, pas un producteur de la barbarie, comme enseigné dans Theodor $W$. Adorno. Après avoir pris contact avec certains types d'aide, nous sommes intéressés à l'étude des pratiques de justice réparatrice qui ont été conçus et mis en ouvre dans différentes parties du monde. Présentera ensuite un bref historique de ces pratiques, leur apparence, leurs arrangements existants, leur extension à certains pays, la reprise de certains de ses concepts et techniques utilisés dans la gestion des situations de conflit hypothèses. Nous présentons aussi le moment de la discussion de la justice réparatrice arrive au Brésil et les premières expériences dans le pays. Notre intérêt principal est de rendre compte des expériences de médiation pour l'école et les conflits communautaires, compte tenu de ce qu'ils apportent ces expériences pour contribuer à la réflexion sur la violence et la barbarie. L'antidote à la barbarie est le pari qui est la clarification, la formation intellectuelle, rationnelle, le mot, par opposition à la force physique, il est possible de préserver finalité humaine dans toutes ses actions. De cela, nous analysons les pratiques de justice réparatrice voient pas quitter leur portée et les limites.

Mots-clés: la violence; l'école; la justice réparatrice; la théorie critique; la médiation des conflits.

Sabemos que a violência nas escolas é um problema que vem preocupando a comunidade escolar, pesquisadores e a sociedade no mundo todo. Notícias de agressões físicas mais ou menos graves entre alunos ou entre alunos e professores e/ou funcionários da escola nos chegam dia após dia, pelos meios de comunicação: jornais e revistas impressos/virtuais, rádios ou manchetes televisivas. Há, no entanto, um exagero midiático ao veicular essas situações de violência em detrimento de outras formas de violência menos visíveis e que alimentam o motor das agressões e crimes que ocorrem na escola. Dessa forma, precisamos deixar claro que reunido sob o termo "violência nas escolas" estão atos e situações de natureza diversa: de agressões graves, passando pelas transgressões às normas disciplinares, aos pequenos atos de incivilidades (ou bullying), tais como: grosserias, desordens, insultos e xingamentos, que continuamente impedem a construção de relações de confiança (Cubas, 2006).

A preocupação com esse tema ocorre porque nos últimos anos novas formas de violência vêm aparecendo nas escolas: a) formas de violência mais graves; b) idade cada vez menor dos alunos envolvidos em situações de violência; 3) ação de agentes externos à escola; 4) acúmulo de situações de conflito não resolvidas, gerando uma sensação de ameaça. Esse último item merece atenção especial por produzir um clima constante de ameaça na escola e ferir a função primordial de formar os sujeitos, em seus aspectos intelectuais, emocionais e interrelacionais. Assim, de instituição protetora de crianças e adolescentes, a escola tem se tornado instituição produtora de ameaça e medo (Cubas, 2006). O que não é novidade se recuperarmos todo o histórico de produção de pesquisas tanto no campo da psicologia escolar como da sociologia e educação (Patto,1990; Saviani, 2009). A violência da escola, como nos lembra Patto (2005), em suas mais diversas práticas, como o estímulo à competição, o autoritarismo, as posturas de indiferença e de omissão, a humilhação social e política do cotidiano escolar à origem social e étnica dos alunos, são formas de educar os homens para a bárbarie, isto é, para o não reconhecimento e a não convivência com a alteridade.

Em seu ensaio "A educação Após Auschwitz", Adorno (1995) afirma a necessidade de repensar o processo e as formas de educação das crianças à medida que Auschwitz, um campo de extermínio científico de judeus, existiu historicamente. Ora, se ele pôde acontecer foi pela ação de homens e mulheres adultos que o tornaram possível. Sendo a educação um espaço de formação do homem que deveria caminhar no sentido da desbarbarização, isto é, como instituição que se moveria no sentido contrário à barbárie. Adorno nos propõe a pensar o que teria feito a Educação, no sentido amplo de todos os espaços e instituições educativas, para a formação de homens capazes de tal barbárie? É nesse sentido que esse trabalho parece oferecer contribuição para pensar o tema da violência nas escolas, levando a ampliação do olhar sobre o tema e a construção de práticas educativas para a convivência com a diversidade.

Essa preocupação se torna clara quando temos notícias de que as tragédias americanas nas escolas da década de noventa, que já são suficientes para pensarmos na expressão da barbárie, foram investigadas pelo Serviço Secreto Americano. As conclusões do relatório final de investigação mostraram que os alunos envolvidos naqueles episódios 
haviam passado por inúmeras situações de humilhação, ameaça e insultos na escola sem que nada tivesse sido feito para nomear e responsabilizar os autores de tais práticas (Morrison, 2005). O que significa dizer que os casos de violência graves encenados na escola nada mais são do que reações a uma história de atos de incivilidades que não puderam ser reconhecidos como violentos e promotores de barbárie (Morrison, 2005). Portanto, lutar para que a barbárie não aconteça é um ato cotidiano de lidar com todas as expressões da violência e conflitos humanos, não no sentido de impedir sua manifestação, mas de compreender e reconhecer as necessidades humanas ameaçadas que encontram respostas no ato da violência. Assim, segundo Adorno (1995, p.158) "a desbarbarização não se encontra no plano de um elogio à moderação, uma restrição das afeições fortes, e nem mesmo nos termos da eliminação da agressão".

No Serviço de Orientação à Queixa Escolar do Instituto de Psicologia da Universidade de São Paulo, temos observado muitas situações de violência produtoras de um sentimento constante de ameaça e insegurança, alimento eficaz da barbárie. No atendimento individual e em grupo de crianças e adolescentes, bem como nos grupos de atendimento às mães que realizamos no segundo semestre de 2009 e no primeiro semestre de 2010, por ocasião do estágio supervisionado do Curso de Aperfeiçoamento em Orientação à Queixa Escolar, constatamos inúmeras situações de maus tratos, negligência, abuso de poder, preconceitos e discriminações sofridas pelos alunos e seus pais em sua relação com a escola. Um menino de 9 anos relatou que sua professora do segundo ano chamava-o constantemente de "branquelo, feio e bobo". Quando a mãe foi conversar com a professora, ela reafirmou as mesmas palavras na frente do menino. A mãe falou com a escola e fez denúncia na Coordenadoria da Educação responsável pelas escolas municipais da região. Nada foi feito. A professora continua trabalhando na escola e nenhuma providência foi tomada. Ela menciona que muitas mães sugeriram a ela que batesse na professora - alguns professores já foram agredidos nessa escola. Mas ela não fez isso. Seu filho, por outro lado, lembra-se dessa cena de horror com frequência com um sentimento de humilhação, injustiça e vergonha. Igualmente nenhuma ação reparadora foi feita. Apenas se viu o tempo passar, esperando-se que ele remediasse a dor daqueles que sofreram tantos processos de humilhação. Não houve nem restauração das relações, nem punição. Nenhuma justiça foi feita seja com ele, seja com sua família. $\mathrm{O}$ menino permanece estudando na mesma escola, porém com outra professora. Ele ainda não aprendeu a ler e escrever e sente-se constantemente vitimizado e ameaçado na escola e em outros lugares, como na Igreja que frequenta, onde é insultado por outras crianças. Nesse caso, podemos ver como relações violentas, do ponto de vista moral, podem ser geradoras de agressões físicas e, mais que isso, constituintes de uma permissividade promotora de assujeitamento. Bater na professora é a possibilidade encontrada por algumas mães de fazer justiça, de não deixar "barato"o que saiu caro a elas e seus filhos, isto é, de responder a uma necessidade psíquica e social de não permitir ser assujeitado pelos outros, de não tolerar o intolerável, mesmo que a saída seja por uma reação de assujeitamento do outro. Na realidade, esse círculo alimentador de violência parte de um pressuposto: "Ou você sobrevive, ou eu" (Balaguer, 2005).

Do mesmo modo, um adolescente relatou sofrer insultos dos colegas que o chamam constantemente de Buster (nome de seu cachorro da raça pit bull). Ele disse um dia aos seus pais que sempre foi chamado assim e que nada foi feito para protegê-lo na escola. Seus pais foram à escola e a escola desconhecia o fato de que era insultado. Ele também relatou um sentimento de impunidade, pois ninguém via suas transgressões às normas disciplinares. Por estar entre "os treze alunos de inclusão da escola", todos o tratavam como "café-com-leite". Ninguém enxergava, portanto, sua potência, nem mesmo quando transgridia. Sentimentos de abandono, ameaça e exclusão são vividos por todos eles constantemente na escola.

Por outro lado, mães relataram a violência produzida por determinadas políticas públicas, como é o caso da progressão continuada. "Eu implorei para que a professora o reprovasse, mas ela disse que não podia fazer isso. Meu filho passou sem saber nada". Sem falar do número de alunos por sala, e dos baixos salários de professores e funcionários. Não se trata também tudo isso de violência? Portanto, vínhamos falando da violência na e da escola, em termos de suas relações interpessoais/institucionais, sem pensar em como as políticas públicas podem atravessar as relações interpessoais/institucionais e serem vitimizadoras da coletividade escolar como um todo: pais, alunos, professores, gestores e funcionários.

Muitos dos alunos e pais atendidos por nós no Serviço de Orientação à Queixa Escolar falam de dores sofridas em processos de conflitos escolares que não foram reconhecidas, faladas, quanto mais tratadas coletivamente. Do mesmo modo, ao realizarmos as visitas às escolas, também ouvimos o mesmo dos professores.

A escola não é, portanto, uma instituição à parte, protegida (e, consequentemente, protetora) dos reveses de nossa forma de estruturação social e econômica. A política neoliberal e seus interesses comparecem na escola de diversas maneiras: pelo arrocho salarial dos professores; pelo argumento econômico de melhoria do fluxo do sistema escolar no que se refere ao regime de progressão continuada (Viégas, 2007); por uma política pública de inclusão dos 
alunos significativamente diferentes que vem de cima para baixo, sem ser discutida e apoiada; pelo número de alunos na sala de aula. Assim, é preciso estender o conceito de violência para além das relações interpessoais e poder ver, nos conflitos que parecem de ordem interpessoal, motivações coletivas, atravessamentos econômicos, políticos e sociais (Souza, 2007). Como nos diz Schilling (s/d):

nossas ações precisam ser multidisciplinares, intersetoriais, multisecretariais. (...) É preciso polícia, justiça, moradia, trabalho, saúde, educação, meio ambiente, cultura, apoio às vítimas, punição e tratamento dos agressores. Há intervenções que podem ser feitas a partir dos recursos próprios, dos recursos pessoais, de cada um de nós. Há ações que só são possíveis a partir da construção de um coletivo, outras que dependem de ações governamentais. (p. 4)

Portanto, qualquer projeto que pretenda intervir nas questões relativas à violência na escola deve partir da perspectiva ampla de que: a) a violência na escola emerge a partir de situações de conflito interpessoais/institucionais; b) a violência está presente nas relações da comunidade escolar - alunos, professores, gestores, funcionários, pais -, mas também nas relações com a comunidade onde a escola se situa (agentes externos de violência); c) a violência pode variar de situações de agressões graves às transgressões às normas disciplinares da escola, até situações chamadas de incivilidades ou bullying; d) a violência costuma estar atravessada por questões coletivas que remetem a determinantes sociais, econômicos, políticos e culturais.

Tendo feito essas considerações, nosso interesse é poder pensar como as práticas restaurativas podem oferecer formas alternativas e complementares ao sistema comum de Justiça de lidar com esse campo de violências na escola, levando em conta a dimensão coletiva e política de sua produção e de sua capacidade de resolução.

\section{As Práticas Restaurativas e Seus Princípios}

É possível notarmos uma série de expressões que circulam no campo social e político e que nos falam de formas de enfrentamento de situações de conflito e violência no mundo: práticas restaurativas, mediação de conflito, escola do perdão e reconciliação, círculos de paz, círculos restaurativos, justiça restaurativa e justiça comunitária. Apesar das diferenças práticas, quiçá conceituais, e de uma possível hierarquização das expressões - Justiça Comunitária, Justiça Restaurativa, Escola do Perdão e Reconciliação, Círculos de Paz e Mediação de conflitos -, o que essas práticas e concepções têm em comum?

Podemos dizer que alguns se equivalem em termos de técnicas de resolução e mediação de conflito, tais como, círculos de paz, escola de perdão e reconciliação, mediação de conflito, círculos restaurativos e etc; enquanto outros se referem a uma conceituação específica, tais como Justiça Restaurativa e Justiça Comunitária. No entanto, todas essas práticas representam uma concepção e intervenção nova de como tratar a dimensão humana do conflito, apoiada em princípios como cultura de paz, democracia participativa, consenso, restauração, cooperação e solidariedade entre os seres humanos (Gomes Pinto, 2005).

A primeira questão que nos é colacada é a de como esse campo de práticas e concepções restaurativas concebe o conflito humano:

O conflito é, pois, parte integrante da vida e da atividade social, quer contemporânea, quer antiga. (...) se origina da diferença de interesses, de desejos e de aspirações. Percebe-se que não existe aqui a noção estrita de erro e acerto, mas de posições que são defendidas frente a outras, diferentes. (...) O conflito pode ocorrer entre duas ou mais pessoas, entre pessoas e grupos, entre grupos, entre pessoas e organizações, entre grupo e organizações. (...) Podemos dizer que o conflito faz parte do processo comum de interação de uma sociedade aberta. (Chrispino, 2002, pp. 29-31)

Portanto, sendo parte da vida, das relações e instituições humanas, o conflito não deve ser visto como um problema e sim como situação capaz de promover um melhor conhecimento de si, dos outros, de nossas relações, das instituições, dos interesses, podendo ser potencializador ou não de mudanças desde que possa ser conduzido não de forma a esgarçar, destruir os laços sociais, mas, ao contrário, na sua dimensão positiva. Para que divergências e diferenças sejam vistas de modo positivo, é necessário que pensemos em ações que não tentem excluí-las, separá-las, segregálas. Em suma, ações que não tentem abafar o conflito, negando as diferenças, mas, ao contrário, que permitam a elas aparecer e ser reconhecidas. Estamos falando da dimensão social do conflito. Freud, por sua vez, tratou também da internalização de dimensões e conflitos sociais no plano dos indivíduos: o psiquismo humano é dotado de instâncias psíquicas que apontam para desejos e necessidades diferentes. Evidentemente, a dimensão interna desse conflito é provocada pelas próprias relações entre o plano da natureza em nós e o plano da cultura (Adorno, 1995).

Um elemento fundamental na construção de novos paradigmas para lidar com o conflito foi a constatação em vários países e, consequentemente, na Organização das Nações Unidas - da ineficácia do Sistema Retributivo, isto é, punitivo, como meio de lidar com os conflitos produtores de crimes e transgresões à lei. Percebeu-se que a punição não 
oferece em si uma forma eficaz de pacificação social uma vez que foi se tornando cada vez mais ampla a necessidade progressiva de criação de vagas e construção de novos prédios prisionais, além dos altos índices de reincidência (De Vitto, 2005; Ministério da Justiça [MJ], 2005). Curiosamente, as práticas alternativas de resolução de conflitos, tais como a Justiça Restaurativa e Comunitária, podem contribuir nas duas pontas da ineficácia do Sistema Judiciário, "tirando alguns conflitos da estrutura clássica do Judiciário e resolvendo aqueles que nunca chegariam a ela, demandas da população economicamente necessitada não chegam, por muitas vezes, às instâncias formais da Justiça" (MJ, 2005, pp. 2-3).

O Conselho Econômico e Social das Nações Unidas (ECOSOC), em sua resolução 1999/26, de 28 de julho de 1999, recomendou que os Estados considerem, no contexto de seus sistemas de Justiça, o "desenvolvimento de procedimentos alternativos ao processo judicial tradicional e a formulação de políticas de mediação e de justiça restaurativa" (MJ, 2005, p. 5).

Em consonância a essa diretriz da ONU, o Ministério da Justiça no Brasil pretende incentivar "o acesso a um sistema de justiça que garanta o cumprimento de direitos e promova equidade" (MJ, 2005, p. 5), como forma de fazer acontecer a paz social. Assim, as novas práticas de intervenção sobre o conflito, conflito que pode promover a violência social e a guerra, pretendem, ao contrário, levar a uma pacificação social, a uma cultura de paz. Não uma paz sem conflitos, uma paz entendida como livre de conflitos, mas sim uma paz com conflitos.

Não por acaso, muito da história da introdução dessas práticas no século XX tiveram origem na experiência do pósguerra. A experiência desastrosa do conflito que produziu e ainda produz situações de violência extrema contra indivíduos, culturas, países e povos e, ao mesmo tempo, experiências de luta social por meio de atividades pacíficas, como a luta de Gandhi na Índia, os maori na Nova Zelândia, bem como as culturas dos povos aborígenas na Austrália e de algumas tradições africanas, parece ter alimentado a necessidade de se pensar em formas pacificadas de responder aos conflitos (Ednir, 2007; Gomes Pinto, 2005; Morrison, 2005).

Considerando então a maneira de enxergar o conflito humano e seu caminho de resolução por meio de formas pacíficas, como as práticas restaurativas veem a sua realização? Por meio de técnicas e práticas que se apoiem em formas de democracia participativa e não representativa, ou seja, a resolução dos conflitos só é possível à medida que se dá a voz direta às partes integrantes do conflito, uma vez que nas palavras de B. Morrison "o conflito pertence a alguém, isto é, é de propriedade de alguém e isso não pode ser roubado" (Palestra sobre Justiça Restaurativa em São Paulo, Secretaria da Justiça, 02/08/2010). Portanto, as decisões não podem ser tomadas por terceiros (advogados, promotores e juízes), mas deve ser assegurada aos verdadeiros participantes da cena conflituosa. Assim, é por meio do diálogo, ou melhor, da rememoração da história do conflito que se pode produzir uma restauração das relações, afetos, traumas e feridas provocadas por ele (B. Morrison palestra sobre Justiça Restaurativa em São Paulo, Secretaria da Justiça, 02/08/2010). A partir daí, pode-se chegar a formas consensuais, cooperadas e solidárias de responder aos danos provocados pelo conflito e assim restaurar as relações.

Todos esses pressupostos parecem muito bonitos em termos teóricos, mas temos uma desconfiança, uma resistência em usar a expressão "paz". Afinal, como pensar em paz num mundo de tanta guerra, violência, conflitos pessoais, coletivos, institucionais, raciais/étnicos, religiosos e territoriais, em que a declaração dos direitos humanos a todo momento parece ser rasgada, abandonada, "carta velha fora do baralho"? Será que isso está apenas no campo da utopia, do sonho, do ideal e que desconfiamos que seja irrealizável? Como pensar em paz social quando a violência comparece como forma reativa de lidar com a dimensão da injustiça e a desigualdade social? E como as novas práticas restaurativas podem tocar e interferir na injustiça e desigualdade social? A retomada histórica das práticas restaurativas bem como de algumas experiências podem nos levar a ter mais elementos para responder a essas questões.

\section{Um Breve Histórico das Práticas Restaurativas}

Como já mencionado anteriormente, as práticas restaurativas são alimentadas pelo movimento do pós-guerra de pensar a produção da paz. Mas as primeiras experiências restaurativas, isto é, de uma outra forma de se interferir nos conflitos humanos e na justiça criminal acontecem todas na década de 70 (Ednir, 2007; Gomes Pinto, 2005).

O resgate das práticas restaurativas tem início no Canadá, em 1975, quando o primeiro modelo Restaurativo de Reconciliação Vítima Ofensor foi introduzido no Sistema Criminal (Ontário). A partir daí, projetos semelhante surgem ao final da década de 70 nos EUA e na Europa (Aústria, Alemanha e Inglaterra). (Ednir, 2007, p. 15)

Nos Estados Unidos, surgiram experiências como as TARC - Técnicas Alternativas de Resolução do Conflito ou RAD - Resolução Alternativa de Disputa -, inicialmente como forma de lidar com os conflitos na terapia de família. Havia em torno de 700 centros públicos e privados das TARC já no final da década de 70 (Morrison, 2005).

Nos anos 90, um segundo modelo restaurativo surgiu na Nova Zelândia, conhecido como Conferências de Grupo 
Familiar, como forma de enfrentar situações de conflito com a lei vividas por adolescentes maori, procurando enfrentar o problema da marginalização e criminalização da cultura maori (Ednir, 2007; Gomes Pinto, 2005; Morrison, 2005).

O terceiro modelo de práticas restaurativas foi o que surgiu na Inglaterra, muito apoiado no modelo da Nova Zelândia, com os chamados Círculos ou Conferências Restaurativas. Outros modelos e práticas surgiram na África do Sul no processo de reconciliação do apartheid; na Colômbia com a ESPERE (Escola do Perdão e da Reconciliação); assim como na Argentina e no Chile (Ednir, 2007).

Notamos, portanto, que grande parte dos modelos de práticas restaurativas parece ter sido recuperado a partir de outras formas de realizar a justiça social utilizados em culturas de povos tradicionais.

Já as intervenções restaurativas no âmbito escolar foram introduzidas na década de 70. Considerando a crescente onda de violência nos EUA, religiosos e ativistas procuravam ensinar à crianças e jovens técnicas de mediação de conflito. Mas foi ao longo da década de 90 que essas experiências ganharam muito maior fôlego com os Programas de São Francisco e Havaí de Resolução de Conflito na Escola ou mesmo em Queensland, na Austrália, nas escolas de ensino médio no enfrentamento de situações de agressões graves e bullying. Desde essa época, o uso de práticas restaurativas tem se expandido em escolas de várias partes do mundo e para o tratamento de uma diversidade de questões: danos à propriedade, roubo, vandalismo, incidentes relacionados a drogas, ociosidade, danos à imagem pública da escola, comportamentos inadequados em sala de aula, ameaças de bomba, assaltos e bullying. Até mesmo o levantamento do Serviço Secreto americano sobre os tiroteios dos anos 90 nos EUA apontaram para a necessidade de ações de prevenção primária, secundária e terciária da violência, apoiadas no modelo de práticas restaurativas (Morrison, 2005).

\section{E no Brasil?}

$\mathrm{O}$ primeiro elemento importante para se pensar a chegada das práticas restaurativas no Brasil é que elas são marcadas por uma recepção institucional e política, centrada tanto em instituições públicas como em organizações nãogovernamentais, sendo esses financiados em grande medida por recursos públicos.

É no âmbito das relações entre o Ministério da Justiça pela Secretaria de Reforma do Judiciário e o PNUD Programa das Nações Unidas para o Desenvolvimento, como proposta recomendada pela ONU- que novos paradigmas de Justiça foram implementados, a partir de 2003, inicialmente como projetos pilotos, e ganharam força cada vez maior, especialmente em diversos espaços de intervenção sobre os conflitos. Como prática alternativa e complementar à Justiça em nosso país, a Justiça Restaurativa e seu modelo foram implementados em dois campos, a partir de 2004, no Projeto Piloto: "Promovendo práticas restaurativas no Sistema de Justiça Brasileiro"; e, anteriormente, em 2000, um projeto piloto de Justiça Comunitária foi iniciado em Brasília. Esse programa veio a se transformar, em 2008, em política pública, tendo recebido destinação orçamentária até 2011 e tendo servido de modelo a implantação de outras práticas alternativas de justiça em diversos municípios do Brasil (MJ, 2008)

O projeto "Promovendo práticas restaurativas no Sistema de Justiça Brasileiro" com inserção em três municípios diferentes, São Caetano do Sul/SP, Porto Alegre/ RS e Brasília/DF, procurava trabalhar nos dois primeiros nas Varas da Infância e Juventude com adolescentes autores de ato infracional e, em Brasília, nos Juizados Especiais Criminais, com práticas restaurativas nem sempre iguais. Nossa jurisprudência permite uma flexibilização muito menor comparada aos países regidos por princípios consuetudinários (commom law), isto é, em que o direito é regido pelos costumes, pelas formas costumeiras de julgamentos de situações precedentes, abrindo espaço para a incorporação de novas práticas sociais. Assim, por ora, apenas no que se refere a essas duas situações legais - Juizados Especiais Criminais e Vara da Infância e Juventude -, sustentadas pelos artigos 126 e 112 na remissão da ação processual no ECA e pelos artigos 98 e 70-74 da nossa Constituição Federal que se pode suspender o processo, segundo Lei 9099/95, e oferecer práticas alternativas de justiça (Gomes Pinto, 2005). Entretanto, ao que parece, a introdução de práticas alternativas de resolução de conflitos pode ser pensada em espaços públicos e coletivos, em situações que ainda não se tornaram crimes ou infrações à lei.

\section{Justiça Restaurativa: Os Círculos Restaurativos}

A seguir, vamos apresentar a metodologia específica utilizada nos círculos restaurativos como forma de se compreender um pouco melhor essa prática.

Os círculos restaurativos têm o objetivo de reunir em seus encontros as partes diretamente e indiretamente marcadas pelo conflito - vítimas, ofensores e comunidade envolvida como forma de reparar danos, restaurar dignidade, segurança e justiça, e reintegrar todos na sociedade. Assim, nossos velhos conhecidos como vítima e ofensor recebem já "de cara" outros nomes na metodologia restaurativa. São autores dos atos conflituosos e receptores, o que já, de princípio, na maneira de nomeá-los pretende compreender que nem sempre vítimas e algozes estão situados em lados opostos e podem então ser pensados como posições dialetizáveis. Além disso, os círculos restaurativos contam com a participação 
fundamental de um mediador ou facilitador do processo retaurativo que não deve ter o papel de juiz, de julgar quem está certo ou errado e distribuir penas ou sanções, mas estar atento aos aspectos objetivos e subjetivos das necessidades dos envolvidos no processo restaurativo.

O processo restaurativo é composto de momentos que se sucedem e que permitem uma escuta das necessidades dos envolvidos no conflito e das possibilidades de ação sobre essas necessidades. Assim, há primeiramente um pré-círculo, o círculo propriamente dito e, por fim, o pós-círculo. Em cada uma dessas etapas são realizadas ações que garantem uma maior eficácia restaurativa. Assim, no pré-círculo pretende-se realizar um trabalho individual de acolhida das partes, entendimento da situação conflituosa e transmissão de informação para cada um dos membros do processo de como funciona o círculo, para que possa participar livremente do processo. Já no círculo restaurativo propriamente dito, há a necessidade de uma compreensão mútua de como o conflito afetou cada uma das partes envolvidas nele, seguida por um processo de responsabilização na situação conflituosa e, por fim, na produção coletiva de um plano de ação capaz de reparar os danos provocados pelo conflito. Já no pós-círculo, é avaliado se o acordo foi cumprido, é celebrada e divulgada para a comunidade a realização do acordo e, quando não há cumprimento do acordo, pensa-se quais necessidades foram atendidas pelo não cumprimento do acordo, isto é, no que o círculo parece ter falhado em termos da escuta das necessidades humanas das partes.

Cada um desses momentos no círculo restaurativo deve ser conduzido por uma pergunta provocadora para cada uma das partes seguido por um momento em que se assegura a escuta e a compreensão mútua dos significados produzidos por cada um sobre o que ocorreu. O que está em questão nos três momentos (pré-círculo, círculo e pós-círculo) é a escuta do que aconteceu, de como o conflito os afetou e de como consertar o dano produzido.

\section{Algumas Práticas Restaurativas no Brasil em Escolas}

Em função da eficácia do projeto piloto, realizado em São Caetano do Sul/SP, iniciou-se em 2006 uma nova fase, dando continuidade na inserção da Justiça Restaurativa, especificamente no município de São Paulo nos distritos próximos a São Caetano do Sul (Melo, 2008). O Projeto Heliópolis e Guarulhos, fruto da parceria do Poder Judiciário com a Secretaria Estadual de Educação do Estado de São Paulo, por meio da FDE - Fundação de Desenvolvimento da Educação - e a COGSP - Coordenadoria de Ensino da Grande São Paulo - em convênio com o Ministério da Educação e da Cultura, pretendia implantar práticas retaurativas em 20 escolas públicas de ensino médio e agentes de práticas restaurativas parceiros no Sistema de Justiça e da Comunidade. Na época desse projeto, eu era psicóloga da instituição "Refazendo Vínculos, Valores e Atitudes" - Serviço de Proteção Jurídico Social e Apoio Psicológico às crianças, adolescentes, jovens e suas famílias, financiado pela Secretaria de Assistência e Desenvolvimento Social do município de São Paulo em parceria com a Faculdade de Serviço Social da PUC - SP - e participamos como instituição da comunidade, recebendo capacitação para realizar os círculos restaurativos no serviço.

Muitas dificuldades foram enfrentadas pelo projeto Heliópolis, tanto na sua implantação nos serviços comunitários, como nas escolas públicas e nas instâncias de Justiça. Segundo Ednir (2007), os desafios gerais do projeto foram: a) atuar dentro de um paradigma dominante que contraria os princípios da inovação restaurativa; b)atuar com parâmetros de tempo inadequado, isto é, uma formação intensa e que precisava permanecer por mais tempo até que os princípios pudessem ser incorporados; e c) conviver com o diferente em todos os níveis, uma vez que três instâncias estavam permanentemente em contato, apontando para as suas diferenças e semelhanças. $\mathrm{Na}$ relação entre justiça e educação, foram observadas dificuldades de superar o constrangimento produzido pelo convite às escolas da região de Heliópolis. Segundo a perspectiva do projeto, superar essa dificuldade seria a primeira das lições, uma vez que a Justiça Restaurativa deve se apoiar do início ao fim num consentimento livre, numa participação democrática e não imposta. Para algumas escolas, o convite se tornou obrigação. Assim, a necessidade de tempo para que as lideranças educacionais, professores e alunos pudessem repensar as formas de lidar com situações de violência - de agressões graves, passando pela indisciplina e pelo bullying - e elaborar os princípios restaurativos era crucial para a implantação bem sucedida do Projeto (Ednir, 2007).

No que se refere ao aprendizado que tivemos no "Refazendo Vínculos, Valores e Atitudes", observamos dificuldades de mudanças institucionais que tornavam a implantação da metodologia praticamente inviável: ausência de espaços na instituição para a realização dos círculos restaurativos, falta de apoio institucional, sobrecarga de trabalho dos facilitadores capacitados para a realização dos círculos restaurativos, além da saída de licença maternidade da psicóloga responsável pela implantação do projeto, entre outros. Além do mais, havia uma cultura institucional pouco responsabilizadora de todos: nem usuários, nem técnicos, nem funcionários eram responsabilizados pelo que ocorria no "Refazendo Vínculos, Valores e Atitudes". Isso produziu inúmeros impasses institucionais, gerando um clima de insegurança, injustiça e falta de confiança na coletividade, uma vez que não havia nem um sistema de punição comum, nem alternativo, o que criava em todos um sentimento 
de descomprometimento com o trabalho. Por parte dos adolescentes, a necessidade de responsabilização era reapresentada cotidianamente à medida que insistentemente realizavam atos coletivos transgressores. Além disso, ao se reunirem em assembléia, os adolescentes pediam por justiça, mesmo que esse pedido viesse sob o signo conhecido da punição. Evidente que aqui estamos relatando em especial a experiência de um dos equipamentos comunitários responsáveis pela realização dos círculos restaurativos. Mesmo assim, realizamos no âmbito do "Refazendo Vínculos, Valores e Atitudes" algumas práticas restaurativas de mediação de situações de conflito, bem como a tentativa de um pré-círculo em situação absolutamente adversa,mostrando o poder dos grupos ligados ao tráfico de drogas na região e suas formas de atuação em situações de conflito. Isso nos fez pensar em: a) a necessidade de usar outra expressão para tratar dos círculos restaurativos de modo a não reinstalar o temor em relação aos órgãos do Sistema Judiciário; e b) necessidade de que o círculo, considerado em seus três momentos, tenha um espaço físico institucional para sua realização. Só assim podemos iniciar a construção de uma cultura institucional e a partir daí estender para uma divulgação comunitária.

Também temos notícias de uma articulação do Poder Judiciário em São Paulo com a Secretaria do Estado da Educação por meio da criação do Sistema de Proteção Escolar, instituído a partir da Resolução SE n. 19/2010, de 19 fevereiro de 2010. Nesse projeto, que representa uma grande ampliação e a viabilização de uma institucionalidade ao Projeto de Justiça Restaurativa nas escolas, pretende-se atuar diretamente sobre a violência nas escolas estaduais de São Paulo por meio de algumas ações integradas que visam à:

- Melhorar o sistema de notificação escolar de situações de conflito oriundos na escola por meio de um sistema virtual de boletim de ocorrências escolares.

- Divulgação de manual e normas gerais de conduta escolar como forma de informar os membros escolares e capacitá-los para lidar com situações de violência na escola, da escola ou que a escola venha a conhecer na comundiade escolar

- Capacitação de dois professores mediadores em cada escola, com carga horária voltada para realizar intervenções restaurativas no ambiente escolar.

Há, ainda, experiências em Minas Gerais, realizadas pelo Programa de Mediação de Conflitos da Secretaria da Defesa Social, criando Núcleos de Prevenção à Criminalidade ou Mediação de Conflito, tanto na capital como em outros municípios, desde 2004. Nesses Núcleos de Mediação de Conflitos há eixos de atuação que vão pensar na mediação de conflitos de atendimento individuais, mediação comunitária e ações e projetos temáticos locais, projetos institucionais capazes de garantir os direitos fundamentais dos cidadãos.
Nesse programa, observamos uma série de ações dos Núcleos de Mediação em situações que envolviam as escolas: depredação dos prédios públicos escolares, relações violentas entre alunos e entre estes e seus professores, ausência de informações nas escolas sobre os direitos fundamentais de crianças e adolescentes, falta de espaços comunitários de cultura, lazer e recriação. As ações dos núcleos foram no sentido de fomentar a prática da metodologia de mediação em contexto escolar, fomentar discussões na escola sobre direitos das crianças e adolescentes, sensibilizações contra violência na escola. Nesse sentido que percebemos que a identificação de demandas coletivas foram traduzidas em intervenções que agissem sobre os fatores de risco coletivo, tornando clara, por vezes, a criação de políticas públicas. Este nos parece ser o grande potencial da Justiça Restaurativa ou Comunitária, ou seja, ao estar mais próxima da comunidade, permitir: a) o acesso à justiça; b) a constatação de demandas coletivas; c) a possibilidade de uma organização coletiva capaz de lutar pela implantação de políticas públicas; e d) a luta pela realização dos direitos fundamentais previstos em nossa Constituição.

\section{Considerações Finais}

As experiências nacionais e internacionais com Justiça Restaurativa nas escolas parecem ter apontado para algumas precauções que devem ser tomadas pelos programas e projetos, que devem pensar em níveis de prevenção, tal como descrito por Morrison (2005). No nível da prevenção primária, a intervenção volta-se para todos os membros da comunidade escolar, visando a imunização e defesa ao crescimento dos conflitos, através de processos de mediação e construção dialógicos entre todos quanto aos afetos, relações, idéias, sentimentos e preconceitos que venham a surgir no cotidiano escolar, particularmente nas situações de resolução de conflitos, particularmente na solução de conflito. Na prevenção secundária, dirige-se a indivíduos específicos e grupos dentro da comunidade escolar, àquelas situações nas quais o conflito é mais prolongado ou envolve número maior de pessoas, devendo acontecer, nesse caso, através da intervenção de facilitador, mediação de iguais e círculos de resolução de conflito. Por fim, a prevenção terciária prevê a participação de ciclo transversal: pais, guardiães, assistentes sociais e outros que tenham sido afetados ou precisam ser envolvidos quando ofensas sérias foram produzidas na escola, sendo que o encontro restaurativo acontece cara-acara.

O protocolo foi criado com base em algumas experiências de escolas americanas e os pontos mais importantes deste são listados na sequência (Chrispino, 2002; Ednir, 2007; Morrison, 2005):

- A Justiça Restaurativa não pode ser um projeto isolado, mas deve fazer parte de um rol de ações 
preventivas da violência e estimuladoras de uma cultura de paz institucional, caso contrário, corre o risco de ainda reproduzir práticas punitivas comuns na comunidade escolar.

- Necessidade de intervenções em conflitos menores e conflitos de dimensões cada vez maiores, pensando em um continuum de práticas restaurativas, das informais para as formais, que possam atender a esse espectro de situações.

- Necessidade de uma participação voluntária das escolas e da comunidade escolar no projeto.

- Necessidade de tempo para a discussão, reflexão e elaboração na comunidade escolar desse novo paradigma de justiça.

- Necessidade de pesquisar modelos que tenham a ver com a escola.

- Diversas práticas restaurativas podem ser combinadas a cada escola.

- Necessidade de criar outras expressões para se tratar as experiências restaurativas para que novamente não se incorra no erro de permanecer no universo do Sistema de Justiça.

Consideramos que as práticas restaurativas, por serem práticas comunitárias, têm um importante papel em levar a justiça aos membros da comunidade, empoderando-a, mobilizando-a e sendo instrumento capaz de organizar a comunidade no sentido do reconhecimento de necessidades coletivas que devem ser endereçadas para o Estado, como forma de cumprir seu papel na garantia dos direitos fundamentais. É isso que percebemos em alguns programas como: nos Núcleos de Mediação, em Minas Gerais; nas experiências de Justiça Comunitária, em Brasília; e na Justiça Restaurativa, em São Caetano do Sul. No projeto Justiça e Educação em Heliópolis e Guarulhos, conquistamos aprendizados no sentido de como garantir ainda que o projeto tenha sua eficácia na mudança institucional dos equipamentos da educação, da justiça e de garantia de direitos na comunidade. Entretanto, ainda não foi possível verificarmos a capacidade da metodologia no sentido de fortalecer laços comunitários e mobilizar a organização comunitária pela luta dos direitos constitucionais.

Em sua definição da barbárie, Adorno (1995) não descarta nem agressão, nem a necessidade da violência como forma de impedir a barbárie. Para ele, certas violências são necessárias para a preservação e luta pela dignidade humana, caso contrário podemos de algum modo igualar ações violentas com finalidades diferentes e cair numa espécie de pacificação social que nada mais é que o outro lado da indiferença, da omissão e da frieza. Para Adorno (1995), “esta passividade inofensiva constitui ela própria, provavelmente, apenas uma forma da barbárie, na medida em que está pronta para contemplar o horror e se omitir no momento decisivo" (p. 164). De todo modo, o antídoto para a barbárie está na aposta feita por ele no esclarecimento, na formação intelectual, racional, na aposta da palavra em oposição à força física, em preservar a finalidade humana em todas as suas ações.

Assim, a forma dinâmica e dialética com que ele pensa os conflitos sociais nos ajuda a refletir justamente no campo das práticas restaurativas a sua potência: a) como prática de uso da palavra para lidar com os conflitos que surgem; b) como momento coletivo de escuta, reflexão, autonomia e empoderamento; c) como momento de ser tocado pelas necessidades do outro e, nesse sentido, produzir uma identificação, oposto do processo de indiferença; e d) como oportunidade coletiva de levantar demandas por direitos fundamentais. Todos esses potenciais as práticas restaurativas parecem ter, embora haja um receio de que sua prática possa produzir um amortecimento dos grandes conflitos sociais à medida em que a responsabilização da comunidade pode significar em certo momento a ausência completa do Estado.

Notamos, ainda, que a desconfiança, o mal-estar, o medo e a insegurança que encontramos nos usuários dos serviços de orientação à queixa escolar, foram provocados por diversas situações de violência vividas na escola - sendo que muitas vezes o próprio fracasso escolar, tanto do ponto de vista do aprendizado como do comportamento, tornouse causa e consequência dessa relação. Assim, intervenções institucionais que recriem um espaço comunitário de reflexão, escuta de necessidades, responsabilização e participação ativa e coletiva na solução das dificuldades, podem ser extremamente potencializadoras de novas práticas escolares comprometidas com os valores fundamentais de nossa sociedade. Além do mais, apostamos no efeito coletivo das práticas restaurativas, frutífero não apenas na mobilização e empoderamento comunitário, mas na luta contra a impunidade, o sentimento de injustiça e de indiferença frequentes em nossa sociedade e, especialmente, na escola. Segundo Boonen (2005), numa intervenção de planejamento estratégico em algumas escolas no projeto Planejar para Integrar Escola e Comunidade, "não se procura o acordo, ou o poder viver em paz apesar dos problemas, mas sim, envolvimento para transformação. A indiferença dos professores é justamente esse continuar a viver apesar dos problemas" (p. 21).

Ao nosso ver, a dimensão profícua das intervenções restaurativas nos conflitos escolares se deve justamente a sua capacidade de produzir um enfrentamento coletivo da dor, por meio de seu reconhecimento, ao invés de negar os conflitos ou ignorá-los. A prova desses efeitos profícuos podemos colher nas experiências de práticas restaurativas de modo geral. Dentre elas, chama nossa atenção os relatos dos trabalhos restaurativos da Comissão de Verdade e 
Reconciliação (CVR) na África do Sul, no pós-apartheid, na década de 90 . Ainda que a justiça não tenha se completado tal como o Congresso Nacional Africano previa, o efeito das conferências de verdade são curiosos para pensarmos na necessidade pública de que certas atrocidadades cometidas contra os direitos humanos possam ser restauradas pela publicização da dor particular dos envolvidos num processo e numa ação coletiva. Portanto, é a necessidade de não esquecer o passado coletivamente, como o que se deu nos processos de anistia, inclusive no Brasil, que fizeram desse procedimento um espaço possível de cura (Endo, 2007).

\section{Referências}

Adorno, T. W. (1995). Educação e emancipação. Rio de Janeiro: Paz e Terra.

Balaguer, G. (2005). Violência e adolescência: Uma experiência com adolescentes internos da FEBEM/SP. Revista Imaginário, 11(11), 91-109.

Boonen, R. (2005). Planejar para integrar escola e comunidade. São Paulo: CDHEP.

Chrispino, A. (2002). Políticas educacionais de redução da violência: Mediação de conflito escolar. São Paulo: Biruta.

Cubas, V. O. (2006). Violência nas escolas: Como definila? In C. Ruotti (Org.), Violência nas escolas: Um guia para pais e professores (pp. 23-54). São Paulo: Andhep/ Imprensa Oficial do Estado de São Paulo.

De Vitto, R. C. (2005). Justiça criminal, justiça restaurativa e direitos humanos. In C. Slakmon, R. C De Vitto, \& R. Gomes Pinto (Orgs.), Justiça Restaurativa (pp. 4152). Brasília, DF: Ministério da Justiça e Programa das Nações Unidas para o Desenvolvimento/PNUD.

Ednir, M. (Org.) (2007). Justiça e educação em Heliópolis e Guarulhos: Parceria para a cidadania. São Paulo: CECIP.

Endo, P. (2007, Agosto). Psicanálise, direito e justiça restaurativa. Encontro promovido em Porto Alegre pelo Projeto Justiça para o século 21 (Versão modificada). Recuperado de http://www.polemica.uerj.br/

Gomes Pinto, R. S. (2005). Justiça Restaurativa é possível no Brasil? In C. Slakmon, R. C De Vitto, \& R. Gomes Pinto (Orgs.), Justiça Restaurativa (pp. 19-40). Brasília, DF: Ministério da Justiça e Programa das Nações Unidas para o Desenvolvimento/PNUD.

Melo, E. R. (2008). Justiça restaurativa e comunitária em São Caetano do Sul: Aprendendo com os conflitos a respeitar direitos e promover a cidadania. Rio de

\section{Janeiro: CECIP.}

Ministério da Justiça (2005). Acesso à Justiça por sistemas alternativos de solução e administração de conflitos: Mapeamento nacional de programas públicos e nãogovernamentais. Brasília: Ministério da Justiça.

Ministério da Justiça (2008). Relato de uma experiência de Justiça Comunitária em Brasília. Brasília: Ministério da Justiça.

Morrison, B. (2005). Justiça Restaurativa nas escolas. In C. Slakmon, R. C De Vitto, \& R. Gomes Pinto (Orgs.), Justiça Restaurativa (pp. 294-319). Brasília, DF: Ministério da Justiça e Programa das Nações Unidas para o Desenvolvimento/PNUD.

Morrison, B. (2010, Agosto 02). Palestra sobre Justiça Restaurativa. São Paulo: Secretaria da Justiça.

Patto, M. H. S. (1990). A produção do fracasso escolar: Histórias de submissão e rebeldia. São Paulo: T. A. Queiroz.

Patto, M. H. S. (2005). Exercícios de indignação: Escritos de educação e psicologia. São Paulo: Casa do Psicólogo.

Saviani, D. (2009). Escola e democracia. Campinas, SP: Autores Associados.

Schilling, F. (n.d). Indisciplina, violência e o desafio dos Direitos Humanos nas escolas. In Programa Ética e Cidadania: Contruindo valores na escola e na sociedade. Recuperado de http://www.dhnet.org.br/ direitos/militantes/flavia_schilling/flavia_schilling_ indisciplina_viol_desafio_dh_escolas.pdf

Souza, B. P. (2007). Funcionamentos escolares e a produção do fracasso escolar e do sofrimento. In B. P. Souza (Org.), Orientação à queixa escolar (pp. 241-278). São Paulo: Casa do Psicólogo.

Viégas, L. S. (2007). Progressão continuada: Uma relação complexa. In B. P. Souza (Org.), Orientação à queixa escolar (pp. 307-328). São Paulo: Casa do Psicólogo.

\section{Endereço para Correspondência:}

Gabriela Balaguer

Endereço: Rua Felisberto Fiori D’Orazio, n ${ }^{\circ} 106$. Santa

Felicidade, Curitiba/PR - CEP: 82410-460.

Email: gabrielabalaguer2014@gmail.com 